\title{
Numerical Analysis of Hot Cracking in Laser-Hybrid Welded Tubes
}

\author{
Moritz Oliver Gebhardt, ${ }^{1}$ Andrey Gumenyuk, ${ }^{2}$ and Michael Rethmeier ${ }^{2}$ \\ ${ }^{1}$ Linkage \& Suspension, TRW Automotive GmbH, LEF, Hansaallee 190, 40547 Düsseldorf, Germany \\ ${ }^{2}$ Division 9.3 Welding Technology, BAM Federal Institute for Materials Research and Testing, Unter den Eichen 87, \\ 12205 Berlin, Germany
}

Correspondence should be addressed to Andrey Gumenyuk; andrey.gumenyuk@bam.de

Received 30 August 2013; Accepted 18 November 2013

Academic Editor: Martha Guerrero

Copyright (C) 2013 Moritz Oliver Gebhardt et al. This is an open access article distributed under the Creative Commons Attribution License, which permits unrestricted use, distribution, and reproduction in any medium, provided the original work is properly cited.

In welding experiments conducted on heavy wall pipes, the penetration mode (full or partial penetration) occurred to be a significant factor influencing appearance of solidification cracks. To explain the observed phenomena and support further optimization of manufacturing processes, a computational model was developed, which used a sophisticated strategy to model the material. High stresses emerged in the models in regions which showed cracking during experiments. In partial penetration welding, they were caused by the prevention of weld shrinkage due to the cold and strong material below the joint. Another identified factor having an influence on high stress localization is bulging of the weld.

\section{Introduction}

Substitution of chipping for a welding process may help to save time and material, especially when high wall thicknesses need to be processed and/or high precision is demanded; as for example, in the production of hydraulics, a beam welding process is beneficial (see $[1,2]$ for details). A problem hindering intense industrial use is the occurrence of weld hot cracking, when the thickness of the weld exceeds $10 \mathrm{~mm}$ [3].

Welding trials conducted at BAM, using tubes with a wall thickness of $14.5 \mathrm{~mm}$ and a comparatively low outer diameter of $136.6 \mathrm{~mm}$ made from low-alloyed fine grain structural steel S460NH, revealed that cracking is closely connected to the penetration mode (full or partial) [2, 4]. Full penetration welds did not show any conspicuous features, as long as tack welds were omitted, but solidification cracks were detected in most welds using partial penetration. Cracks were either found at the lower end of the weld cross sections (from now on called the root) or in the middle of the weld, where a localized rise of the weld seam width (bulging) existed.
The report at hand tries to give an answer to (1) why partial penetration welds are more prone to hot cracking than full penetration welds and (2) which role the bulging plays in the content. A numerical model, using a sophisticated material modeling strategy, was employed to achieve this goal.

Solidification cracks emerge in the last stages of solidification when liquid is still present around the growing dendritic network. There is a stage between the start and end of solidification, where the material, even though ductile, shows brittle behavior [5]. The end of solidification in this content is the temperature where really all of the material is solidified which may be well below the point in time, when the body shows solid behavior macroscopically. Consequently low melting phases, like Fe-S (isothermal eutectic solidus temperature of $988^{\circ} \mathrm{C}$ [6]) play an important role in the content.

Important impact factors are the mechanical conditions encountered in the region under solidification, either via applied boundary conditions [7-10] or by the material itself. 
In particular when welding high strength steel, the developing stresses can be high [9]. Their sway on the hot crack prone region needs close observation.

The reason for hot crack occurrence is not conclusively known [6]. Experimental evaluation at temperatures close to the solidus temperature is difficult and hence "an educated guess frequently replaces experimental proof” [11]. A common belif is that hot cracking is caused when the strains in the mushy zone $[5,12,13]$ or the macroscopic outward movement of its edges $[14,15]$ exceeds a material dependent threshold value. Others linked crack nucleation to a pressure drop in the mushy interval [16-18]. Shibahara and coworkers [19-23] successfully used methods from structural fracture mechanics, which included evaluation of a bonding stress for the purpose of crack initiation and evolution. The influence of the triaxiality of the stress state is hardly taken into account in the discussion. But it was already remarked by Borland and Younger [24] in 1960 that the triaxiality may cause high stresses in the vulnerable zone, even though it is considerably soft.

When trying to understand the impact of mechanical and thermal boundary conditions on weld hot cracking, the mechanical reactions inside the vulnerable zone are of interest. Consequently, close attention must be taken when choosing material properties, particularly above $1000^{\circ} \mathrm{C}$, including the liquid-solid transition and the liquid region. The purpose of the last point is not to simulate transport phenomena but to produce, at least qualitatively, a reasonable mechanical answer.

Steel melt is a liquid of the Newton type [25] with a viscosity comparable to water. Accordingly, three main features have to be modeled. The first one is a very low resistance against distortion. The second one is a considerable resistance against compression and expansion. When melting and solidification of a material are necessary to be evaluated, the third feature to model is a harsh drop in viscosity upon melting and a strong rise in viscosity during solidification.

\section{Finite Element Model}

2.1. Boundary Conditions. A rotational symmetry model was employed to allow usage of a fine mesh at a feasible computation time. Hence the computational domain was a cross section of the weld. Two models were built up. One model represented a partial penetration weld; the other one simulated a full penetration one. Both models used the same mesh made from parabolic quadrilaterals, with a maximum edge size of $0.11 \mathrm{~mm}$ at the weld symmetry line. The excess filler material of the full penetration model was deleted in the partial penetration one. The root in the full penetration model was constituted out of deformed weld metal.

Contact elements attached to the nodes at the symmetry line allowed retreat of the nodes from the symmetry line but prohibited its penetration. Nodes heated above solidus were bound to the symmetry to simulate the joining process. On the side of the tube far away the joint, spring elements represented the stiffness of the surrounding construction.

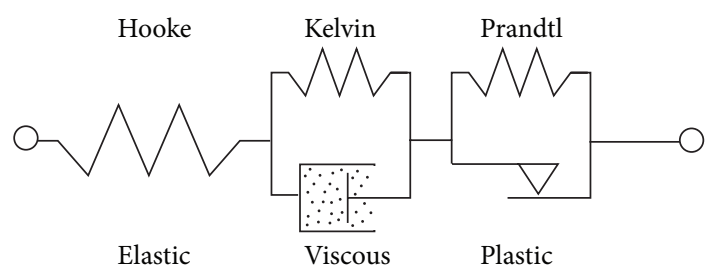

FIGURE 1: Simplified sketch for a material model ranging from ambient temperature up to the melt.

The welding heat was input using four double ellipsoidal shaped power density distributions. Heat transport across the free boundaries was neglected due to the high relation of volume versus surface of the tubes. A convection boundary condition at the clamping side of the model represented its heat sink.

The filler material was brought into the model using a dead/alive technology. It was revived, when the arc center crossed the computational plane.

2.2. Material Model. The material in the experiments was the low-alloyed high strength fine grain steel S460NH. It had an elastic limit $R_{p 0.2}$ of $455 \mathrm{MPa}$ and a tensile strength $R_{m}$ of $625 \mathrm{MPa}$. While the thermophysical part of the applied material model was very much straight forward, the thermomechanical part of the model can be displayed as a sequential Hooke-Kelvin-Prandtl model (Figure 1). A limitation is that the picture is only valid for a one-dimensional test, without revolution of the force direction. As all three parts were arranged sequentially, it was always the softest part that defined the stress/strain state of the whole pattern. The Hooke part, on the left-hand side in Figure 1, was active for small strains, independent of the temperature. The Prandtl part represents the plastic part of the material model and was active for temperatures below $900^{\circ} \mathrm{C}$ only. A Kelvin model, symbolized by a damper parallel to a spring, stands for the viscoplastic part, which was active for temperatures $>900^{\circ} \mathrm{C}$ only.

2.2.1. Material Properties Origin. The thermophysical material properties for the whole temperature range and the thermomechanical material properties for temperatures up to $900^{\circ} \mathrm{C}$ were taken from the SYSWELD material database [26] and were also published in [27]. The sources provide material properties for the solid phases ferrite, austenite, and martensite. Their values were originally designed to simulate S355J2G3. But despite the nominal difference in the yield strength of more than $100 \mathrm{MPa}$, the ferrite $\sigma$ - $\varepsilon$-curve at $20^{\circ} \mathrm{C}$ fitted nearly perfectly the in-house measured curve of the tube material. The thermophysical and linear mechanical properties are within a narrow band for low-alloyed steels anyway $[28,29]$. For this reason, the ferrite properties from the source were taken as base material values. The thermal strain data was provided by an author of [30] and originally measured at S690QL using heating and cooling rates typical for beam welding. Extra thermal strains during melting and solidification were also included. 
TABle 1: Parameters of the viscoplastic model used (see [31]).

\begin{tabular}{lccc}
\hline & $20^{\circ} \mathrm{C}$ & $900^{\circ} \mathrm{C}-1440^{\circ} \mathrm{C}$ & $1500^{\circ} \mathrm{C}$ \\
\hline$C_{1}$ & $4.37 \times 10^{-2}$ & $C^{(1 / m+1)}$ & $8.83 \times 10^{1}$ \\
$C_{2}$ & 8.92 & $n /(m+1)$ & 1.10 \\
$C_{3}$ & -1.93 & $m /(m+1)$ & $-5.85 \times 10^{-2}$ \\
$C_{4}$ & $1.26 \times 10^{5}$ & $\mathrm{Q} /(m+1)$ & $1 \times 10^{-4}$ \\
\hline${ }^{*} C$
\end{tabular}

2.2.2. Solid State Phase Transformation. In the beam welding processes modeled, the cooling rates are high and the resulting $t_{8 / 5}$-times could readily be $1 \mathrm{~s}$ [10]. As a result, all the welded and heat affected material considered transform to martensite [30]. In this case a simple phase transformation model was applicable. The material of all elements which were heated above $A_{C 3}$ was exchanged when they started to cool down to a material that used martensitic material properties $(\sigma$ - $\varepsilon$-curve, $E, \nu, \rho, \lambda$, and $h$ ) below the martensite finish $\left(M_{F}\right)$ temperature and austenitic properties above. To further enhance the model, a third material was included which was assigned to elements which had a peak temperature between $A_{C 1}$ and $A_{C 3}$. It was composed of $50 \%$ each out of base material and martensite properties below $M_{F}$ and of $50 \%$ each out of base material and austenite properties above $M_{F}$.

2.2.3. High-Temperature Region. The (austenite) $\sigma$-e-curve from $900^{\circ} \mathrm{C}$ was retained for temperatures above. The Kelvin model from Figure 1 symbolizes a viscoplastic strain hardening model fitted by Kozlowski et al. [31] to measurements from Wray [32] and Suzuki et al. [33] on low-alloyed steels:

$$
\dot{\varepsilon}=C_{1} \cdot \sigma^{C_{2}} \cdot \varepsilon^{C_{3}} \exp \left(\frac{-C_{4}}{T}\right) .
$$

The constants $C_{1}$ to $C_{4}$ are given in Table 1. $C, m, n$, and $Q$ have to be taken from [31] and were evaluated for the presented model at a $C$-content of $0.2 \mathrm{wt}$ - $\%$. For temperatures below $900^{\circ} \mathrm{C}$, the value of $C_{4}$ was linearly increased at $20^{\circ} \mathrm{C}$ to 3.5 its value at $900^{\circ} \mathrm{C}$. This allowed a smooth transition of the two models.

2.2.4. Molten State. From the solidus temperature up to the liquidus temperature, the material becomes a Newtonian fluid; that is, stresses based on deviatoric loads are solely dependent on the strain rate, and the stress versus strain rate curve crosses the origin. At the same time, the viscosity drops by several orders of magnitude, and distortions meet only little resistance. In contrast to the viscosity, the bulk modulus remains nearly constant at the solid-liquid transition [34] and the material keeps its resistivity against hydrostatic loads. When $C_{2}$ is set to zero and $C_{3}$ is set to one, the Kelvin model collapses to a Maxwell model $[25,35,36]$ (a damper serial to a spring):

$$
\sigma_{i j}=-p \delta_{i j}+2 \eta \varepsilon_{i j}
$$

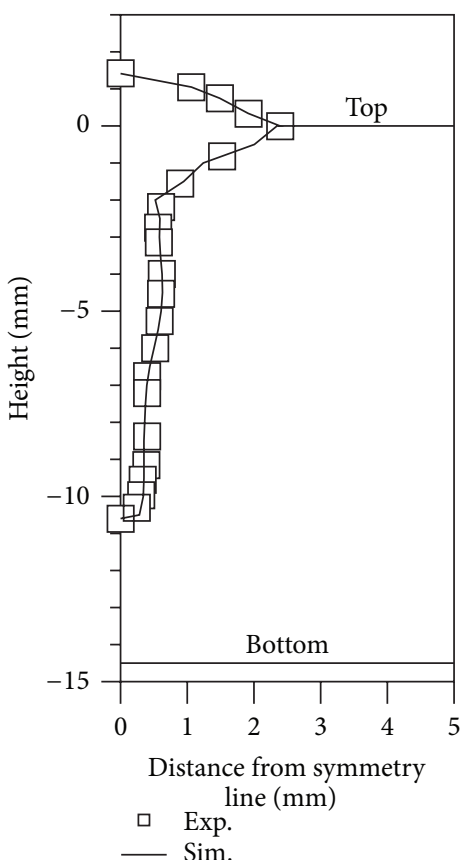

(a) Cross section

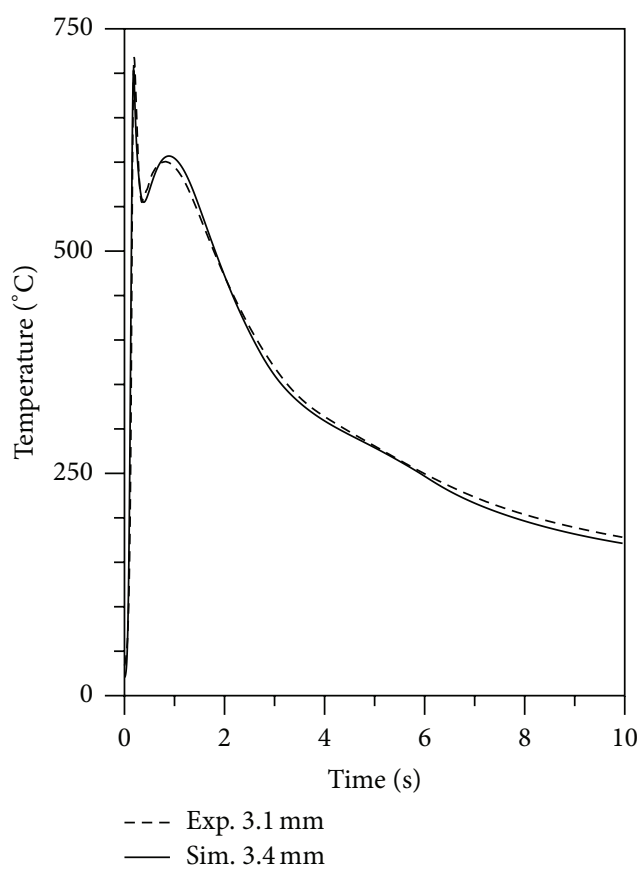

(b) Temperature versus time

Figure 2: Comparison of the temperature field between experiments and the computational model for partial penetration.

The model can then be used to simulate a Newtonian fluid, with a viscosity of

$$
\eta=\eta(T)=\frac{1}{C_{1}} \cdot \exp \left(\frac{C_{4}}{T}\right) .
$$

By a strong reduction of $C_{4}$, the temperature dependence of the viscosity vanishes and is only controlled by $C_{1}$. In trying to 


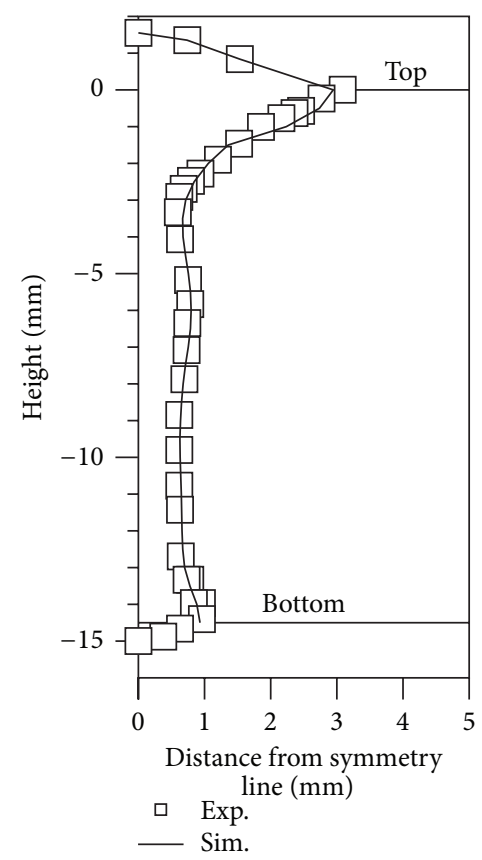

(a) Cross section

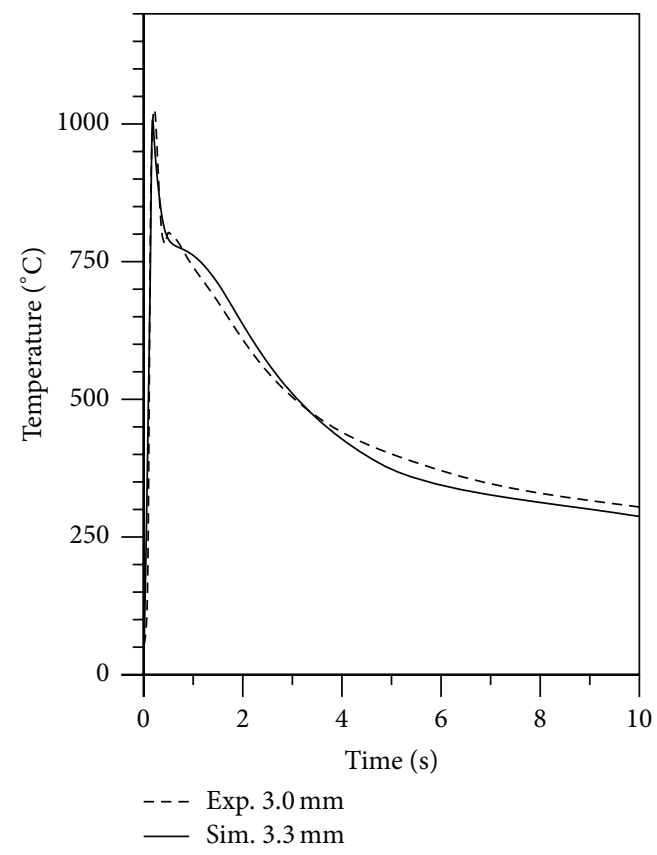

(b) Temperature versus time

FIgURE 3: Comparison of the temperature field between experiments and the computational model for full penetration.

adjust $C_{1}, C_{2}, C_{3}$, and $C_{4}$ to values as explained above while maintaining converged solutions, the parameters in Table 1 were determined.

2.3. Thermophysical Model Part Quality. The thermophysical part of the numeric model was a load to the thermo-mechanical model, and so its quality is vital for the mechanic results. Figure 2 compares the computed

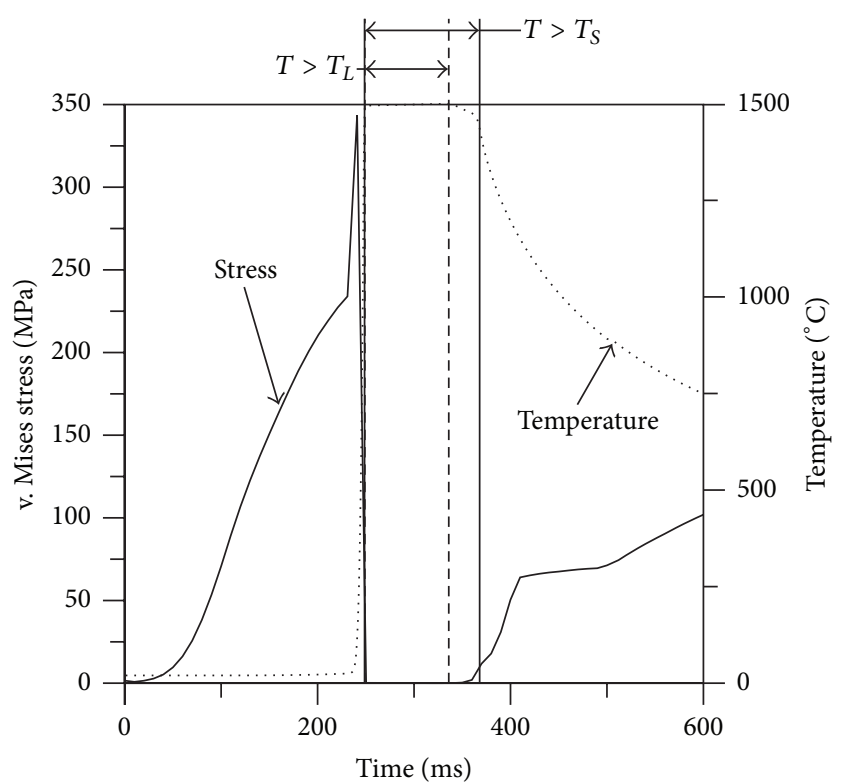

FIgURE 4: v. Mises stress and temperature of a node from the middle of the weld pool. In the figure, $T_{L}$ stands for the liquidus temperature, while $T_{S}$ denominates the solidus temperature.

temperature field in the partial penetration model against experimentally acquired values.

The left-hand side, Figure 2(a), makes a comparison between the maximum of the $1500^{\circ} \mathrm{C}$ isothermal and the experimental cross section. In Figure 2(b), the temperatures at the outer diameter in distance of $3.1 \mathrm{~mm}$ form the symmetry line are compared with experimental temperature measurements using thermocouples type $\mathrm{K}(\mathrm{Ni}-\mathrm{CrNi})$ at the outer diameter in a distance of $3.4 \mathrm{~mm}$ from the symmetry line. The difference between the cross section areas was $0.37 \%$, and the differences in the peak temperatures were $1.99 \%, 1.05 \%$, and $1.05 \%$ for the global maximum and the smaller local maximum and minimum, respectively.

Figure 3 shows equal values for full joint penetration. The cross section areas differed by $2.6 \%$; the peak temperatures and the temperatures to which the temperature field converged at a time of $10 \mathrm{~s}$ had differences of $1.8 \%$ and $5.6 \%$ of the experimental values, respectively.

Both cross sections displayed bulging around approximately $-7 \mathrm{~mm}$.

2.4. Mechanical Reproduction of the Molten State. Figure 4 shows the temperature and the v. Mises stresses at a point in the middle of the weld in the partial penetration model. The v. Mises stresses showed a harsh drop when the solidus temperature was reached and a strong rise after passing the liquidus temperature during cooling. During the molten stage (i.e. $T>T_{L}$ ), the stresses were approximately zero.

\section{Results}

The transversal stresses in the partial penetration model $10 \mathrm{~ms}$ after the laser passed the computational surface are displayed 


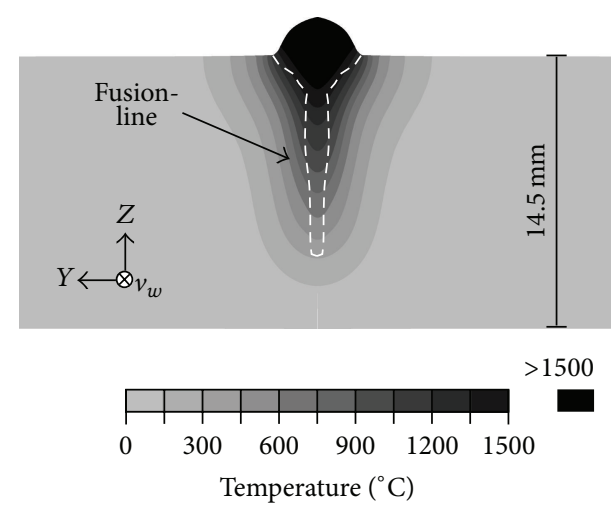

(a)

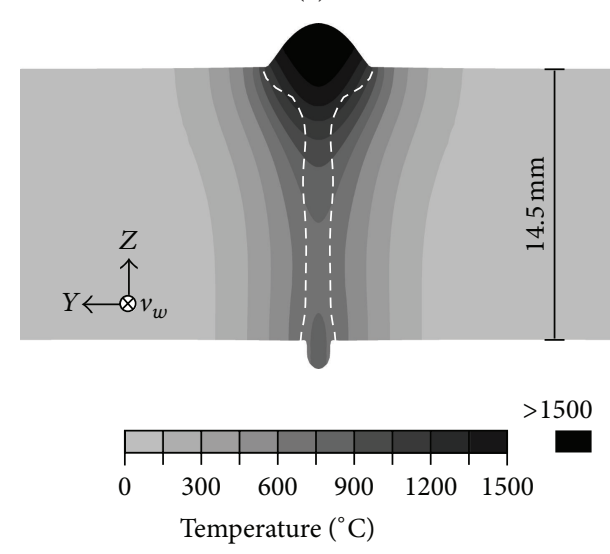

(c)
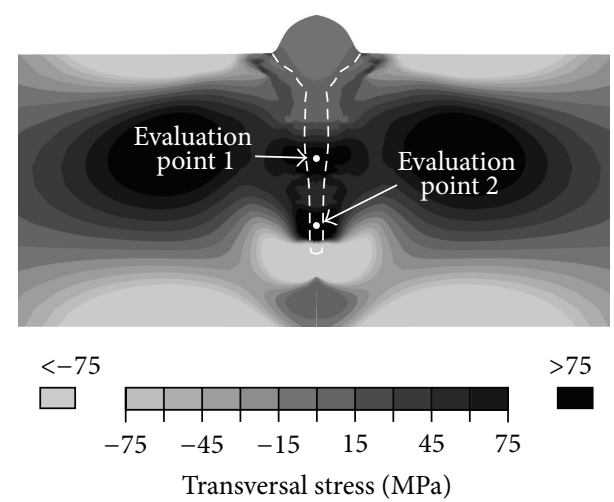

(b)

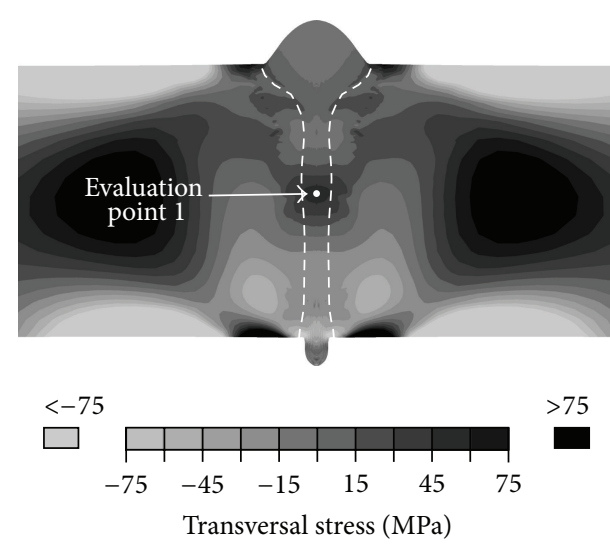

(d)

Figure 5: Temperature and v. Mises stresses in the computational model $10 \mathrm{~ms}$ after the laser beam center passed the computational domain. The figures show halves of cross sections reflected along the weld symmetry line.

in Figure 5(a). Two maxima, representing tensile stresses, could be found in the cross section. One was located in the bulging region and the other one in the root of the weld. This correlates with the spaces, in which cracks were found during experiments. Strong compressive stresses were visible in the region below the weld.

Obviously, the lower tensile maximum and the high levels of compressive stress below the weld were missing in the full penetration model (Figure 5(b)). But the maximum in the bulging region was retained, though, at a lower amplitude.

Figure 6 shows the evolution of the stresses during cooling in both models. The displayed values were taken from the respective evaluation points in Figure 5. Their orientation is given with respect to the welding direction.

The level of the computed stresses per se was striking. They easily overshot $100 \mathrm{MPa}$, and the longitudinal stresses even reached $200 \mathrm{MPa}$. It is visible that the highest stresses were by far the stresses in the root of the partial penetration model. They were followed by the stresses in the bulging region. Despite a very short sequence in the vertical direction at about $1250^{\circ} \mathrm{C}$, the lowest stresses were found in the bulging region of the full penetration model. The stress levels in the bulging region of the two models differed widely when it came to lower temperatures, but they were of the same magnitude.

\section{Interpretation}

Due to the triaxiality of the stress state, the stresses can be high in the vulnerable zone, even though the material is soft. Since the hydrostatic part of the stress tensor is elastic, high levels of stress can exist, without the need for high strains. The existence of high stresses in the weld is in correlation with the compilation of Borland and Younger [24] and the works of Shibahara et al. [19-23].

The effect of the stresses can be pictured as follows. If rest of melt is trapped in the growing dendritic network, it will be subject to a negative pressure and may thus experience cavitation. Other than a liquid, the resulting gas can hardly sustain any stress and fails to support the dendrites, which become more vulnerable to applied loads.

The cold and strong material below the weld in partial penetration works like a local restraint and impedes weld shrinkage, causing the increased root side stress levels. If it is true that stresses cause crack emergence, then this is the root cause for the observed effect that partial penetration welds are more prone to solidification cracking than full penetration ones. This result corresponds to examinations by Quiroz et al. [9].

The bulging region is special as the molten pool has a local maximum in its width and as this region solidifies 


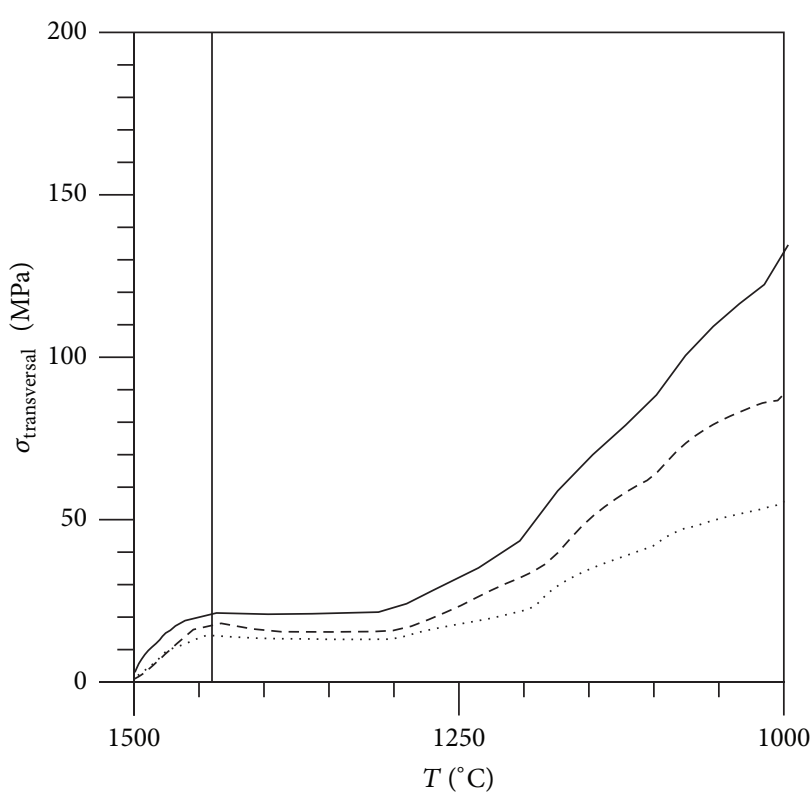

(a)

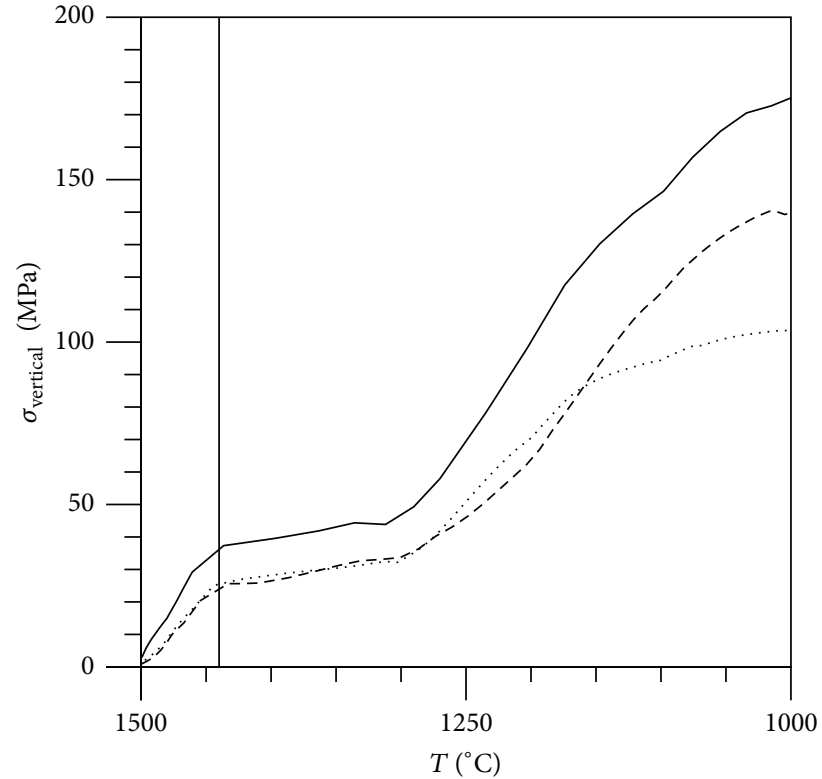

(b)

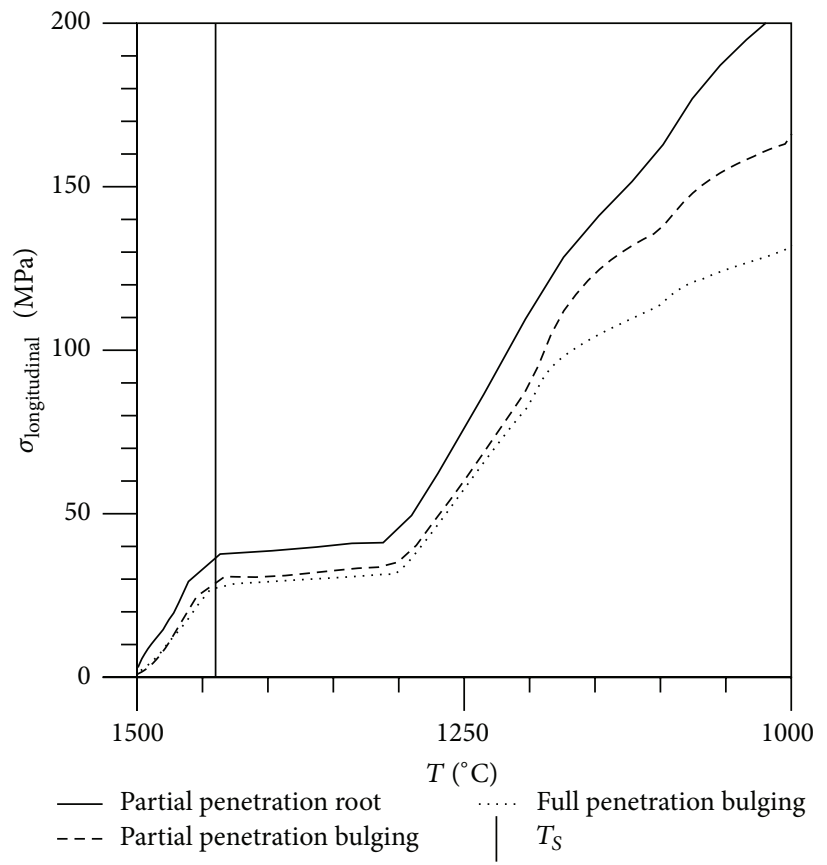

(c)

FiguRE 6: Stresses in the three spatial directions in both models. The figure gives values at the bulging region of both models and at the root of the partial penetration model.

after the parts of the weld above and below do. Weld hot cracks are regularly found in this zone. Both models displayed a maximum in the tensile stresses here. This is a strong indication that the correlation of hot cracks with bulging is not coincidental. The stresses are only caused by the interaction of the temperature field with the material. When the material in the weld solidifies, stresses caused by the thermal strains during solidification are relieved as long as connection to the melt is available. But when the bulging region solidifies, the material around is already in the solid state and the whole amount of thermal strain adds to the stresses.

The stresses in the bulging region are higher in the partial penetration model, even though the bulging region and the height of the weld in the full penetration model are larger. The reason for this is most probably also found in the cold material below the weld. The material below the weld impedes the shrinkage, so the weld material is wider than it would 
be without the extra boundary condition (hence the tensile stress). Consequently, tensile stresses are aggravated in a large part of the weld. Additionally, the stiffness of the cold material is bigger than that of warm weld material due to the temperature.

\section{Conclusion and Outlook}

Two models, representing partial and full penetration laserGMA-hybrid welding experiments on thick-walled tubes, were built up to assess the mechanical reaction of the weld material at temperatures where solidification cracking happens. The reason was to understand why partial penetration welds were more prone to hot cracking than full penetration ones, during the experiments. A sophisticated material modeling strategy was developed, which used a viscoplastic model in the high temperature region and considered solid state phase transformation. By collapsing the viscoplastic part of the material model into a Maxwell model upon melting, the melt was modeled mechanically as a viscous Newton fluid.

The results showed high stresses in regions, where solidification cracks were found in the experiments, with higher levels in the partial penetration model. Those stresses are possible due to the triaxiality of the stress state. In the root of the partial penetration model, they were caused by the impedance of weld shrinkage due to the cold and strong material below the weld. The stress maximum in the bulging region, found in both models, was caused by the inhomogenous cooling of the weld and presumably aggravated in partial penetration welding due to the cold material below the weld.

Further attention is needed to clarify the connection between partial penetration and the stress maximum in the bulging region. Other experimental results, for example, the influence of the laser beam power and the wire feed speed on hot cracking, have to be analyzed in future times.

\section{References}

[1] M. Gebhardt, A. Gumenyuk, and M. Rethmeier, "Single-run high power laser-GMA-hybrid-welding of thick walled tubes," Welding Journal, vol. 91, no. 6, pp. 55-61, 2012.

[2] M. Gebhardt, A. Gumenyuk, V. Quiroz, and M. Rethmeier, "Laser-MSG-hybridschweißen dickwandiger präzisionsrohre," Schweißen und Schneiden, vol. 64, no. 5, pp. 254-259, 2012.

[3] J. Schuster, Heißrisse in Schweißverbindungen, DVS, Düsseldorf, Germany, 2004.

[4] M. Gebhardt, A. Gumenyuk, and M. Rethmeier, "Laser-MSGhybridschweißen dickwandiger präzisionsrohre," Final Report of the AiF-Project 15917N, BAM Bundesanstalt für Materialforschung und -prüfung, Berlin, Germany, 2011.

[5] N. Prokhorov, "The technological strength of metals while crystallising during welding," Tech. Rep., 1965.

[6] C. Cross, "On the origin of weld solidification cracking," in Hot Cracking Phenomena in Welds, H. Herold and T. Böllinghaus, Eds., pp. 3-18, Springer, Berlin, Germany, 2005.

[7] C. E. Cross and T. Boellinghaus, "The effect of restraint on weld solidification cracking in aluminium," Welding in the World, vol. 50, no. 11-12, pp. 51-54, 2006.
[8] T. Kannengiesser and A. Kromm, "Design-specific influences on local weld displacement and hot cracking," in Proceedings of the 2nd International Conference on Welding and Joining of Materials (ICWJM '07), pp. 1-9, Cusco, Peru, 2007.

[9] V. Quiroz, M. Gebhardt, S. Gook, A. Gumenyuk, and M. Rethmeier, "Hot cracking in high power laser beam welding of thick high strength structural steels under restraint conditions," in Proceedings of the 29th International Congress on Applications of Lasers and Electro-Optics (ICALEO '10), pp. 225-232, Laser Institute of America, San Diego, Calif, USA, September 2010.

[10] M. Gebhardt, V. Quiroz, A. Gumenyuk, and M. Rethmeier, "Restraint effects on stresses and strains in single-run high power laser beam welding of thick plates," in Mathematical Modeling of Weld Phenomena 9, H. Cerjak and N. Enzinger, Eds., pp. 1011-1033, Technischen Universität Graz, Styria, Austria, 2010.

[11] D. G. Eskin and L. Katgerman, "A quest for a new hot tearing criterion," Metallurgical and Materials Transactions A, vol. 38, no. 7, pp. 1511-1519, 2007.

[12] H. Bergmann and R. Hilbinger, "Numerical simulation of centreline hot cracks in laser beam welding of aluminium close to the sheet edge," in Mathematical Modeling of Weld Phenomena 4, H. Cerjak, Ed., pp. 658-668, Technischen Universität Graz, Styria, Austria, 1998.

[13] R. Hilbinger, H. Bergmann, W. Köhler, and F. Palm, "Consideration of dynamic mechanical boundary conditions in the characterization of a hot cracking test by means of numerical simulation," in Mathematical Modeling of Weld Phenomena 5, $\mathrm{H}$. Cerjak, Ed., pp. 847-862, Technischen Universität Graz, Styria, Austria, 2001.

[14] V. Ploshikhin, A. Prikhodovsky, A. Ilin, C. Hermdinger, and F. Palm, "Mechanical-metallurgical approach for prediction of solidification cracking in welds", in Mathematical Modeling of Weld Phenomena 8, pp. 87-104, Technischen Universität Graz, Styria, Austria, 2007.

[15] V. Ploshikhin, A. Prihodovsky, and A. Ilin, "Experimental investigation of the hot cracking mechanism in welds on the microscopic scale," Frontiers of Materials Science in China, vol. 5, no. 2, pp. 135-145, 2011.

[16] M. Rappaz, J.-M. Drezet, and M. Gremaud, "A new hot-tearing criterion," Metallurgical and Materials Transactions A, vol. 30, no. 2, pp. 449-455, 1999.

[17] C. Monroe and C. Beckermann, "Development of a hot tear indicator for steel castings," Materials Science and Engineering A, vol. 413-414, pp. 30-36, 2005.

[18] I. Farup and A. Mo, "Two-phase modeling of mushy zone parameters associated with hot tearing," Metallurgical and Materials Transactions A, vol. 31, no. 5, pp. 1461-1472, 2000.

[19] M. Shibahara, H. Serizawa, and H. Murakawa, "Finite element method for hot cracking using interface element," Transactions of the Japan Welding Research Institute, vol. 28, no. 1, pp. 47-53, 1999.

[20] M. Shibahara, H. Serizawa, and H. Murakawa, "Finite element analysis for hot cracking on transverse cross section using temperature dependent interface element (report ii)," Transactions of the Japan Welding Research Institute, vol. 29, no. 1, pp. 59-64, 2000.

[21] M. Shibahara, H. Serizawa, and H. Murakawa, "Finite element analysis of hot cracking under welding using temperaturedependent interface element," in Proceedings of the 11th International Offshore and Polar Engineering Conference, I. Langen, 
T. Yao, J. Koo, R. Knapp, and J. Chung, Eds., vol. 4, pp. 297303, The International Society of Offshore and Polar Engineers, Stavanger, Norway, June 2001.

[22] M. Shibahara, H. Nagaki, S. Takaba, H. Serizawa, and H. Murakawa, "Prediction of hot cracks of T-joints in fullpenetration welding process," Welding in the World, vol. 53, no. 11-12, pp. 312-321, 2009.

[23] M. Shibahara, T. Iwamoto, T. Osuki, K. Ogawa, H. Serizawa, and H. Murakawa, "Numerical analysis of hot cracking in welded pipe structure," Transactions of the Japan Welding Research Institute, pp. 97-98, 2011.

[24] J. Borland and R. Younger, "Some aspects of cracking in welded cr-ni austenitic steels," British Welding Journal, vol. 7, no. 1, pp. 22-59, 1960.

[25] B. Thomas and M. Bellet, "Modeling of stress, distortion and hot tearing," in ASM Handbook, D. Stefanescu, Ed., vol. 15, pp. 449-461, American Society of Metals, 2008.

[26] ESI Group, “Material database," 2009.

[27] J. Hildebrand, Numerische schweißsimulation. bestimmung von temperatur, gefüge und eigenspannung an schweißverbindungen aus stahl- und glaswerkstoffen [Ph.D. thesis], BauhausUniversität Weimar, Weimar, Germany, 2009.

[28] F. Richter, Physikalische Eigenschaften von Stahlen und Ihre Temperaturabhangigkeit, Stahleisen-Sonderbericht, Stahleisen, Düsseldorf, Germany, 1983.

[29] F. Richter, Die Wichtigsten Physikalischen Eigenschaften Von 52 Eisenwerkstoffen, Stahleisen-Sonderbericht, Stahleisen, Düsseldorf, Germany, 1973.

[30] U. Dilthey, P. Seyffarth, A. Gumenyuk, K. Woeste, and A. Scharff, Mathemathische Simulation der Gefügeentwicklung und der Sich Einstellenden Mechanischen Eigenschaften Elektronenstrahlgeschweißter Verbindungen von Stahlwerkstoffen, Deutsche Forschungsgemeinschaft, Bonn, Germany, 2001.

[31] P. F. Kozlowski, B. G. Thomas, J. A. Azzi, and H. Wang, "Simple constitutive equations for steel at high temperature," Metallurgical Transactions A, vol. 23, no. 3, pp. 903-918, 1992.

[32] P. J. Wray, "Effect of carbon content on the plastic flow of plain carbon steels at elevated temperatures," Metallurgical Transactions A, vol. 13, no. 1, pp. 125-134, 1982.

[33] T. Suzuki, K.-H. Tacke, K. Wuennenberg, and K. Schwerdtfeger, "Creep properties of steel at continuous casting temperatures," Ironmaking and Steelmaking, vol. 15, no. 2, pp. 90-100, 1988.

[34] C. Li and B. G. Thomas, "Thermomechanical finite-element model of shell behavior in continuous casting of steel," Metallurgical and Materials Transactions B, vol. 35, no. 6, pp. 1151-1172, 2004.

[35] J. Lemaitre and J. L. Chaboche, Mechanics of Solid Materials, Cambridge University Press, Cambridge, UK, 2002.

[36] H. E. Siekmann, Strömungslehre-Grundlagen, Springer, Berlin, Germany, 1st edition, 2000. 

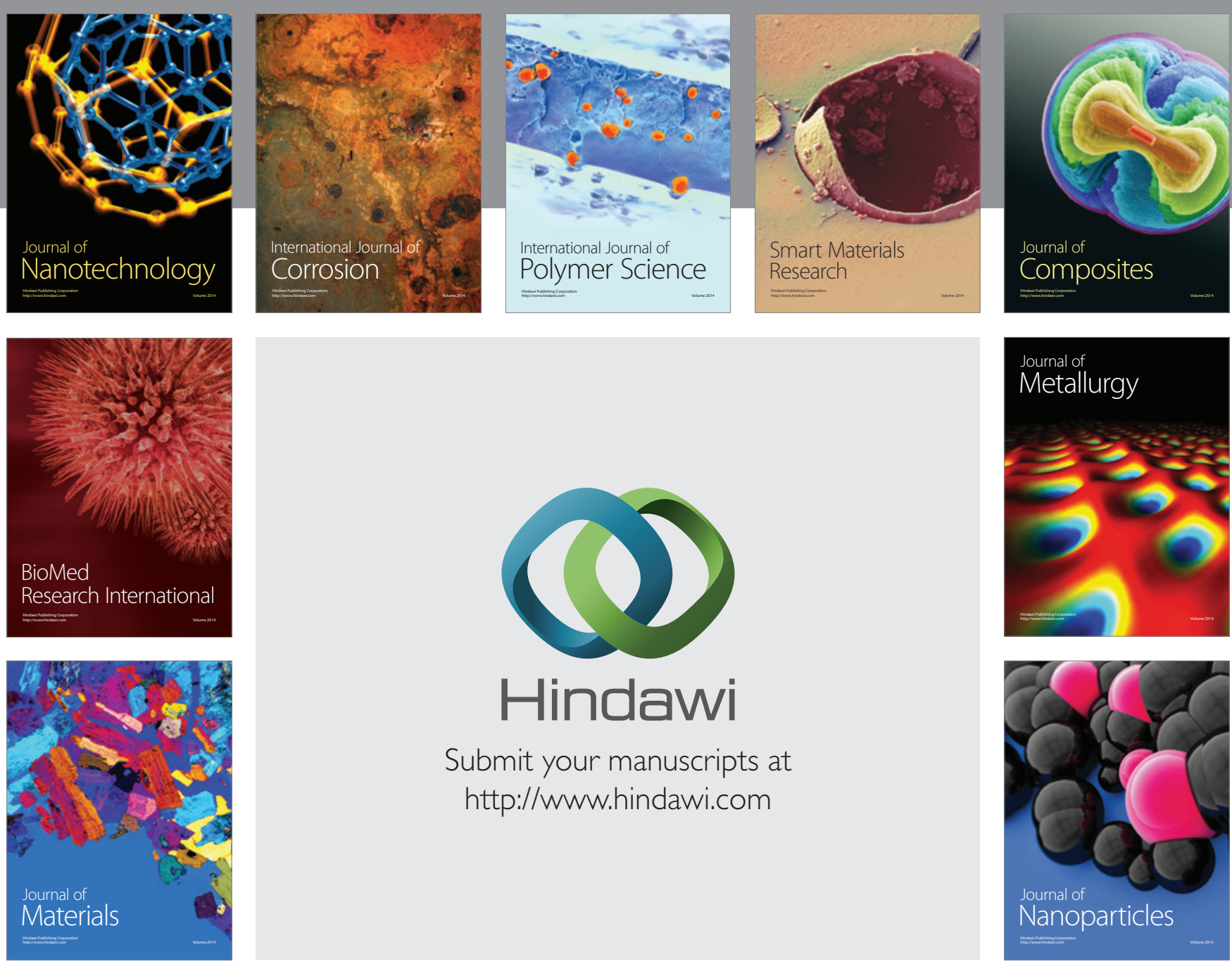

Submit your manuscripts at http://www.hindawi.com
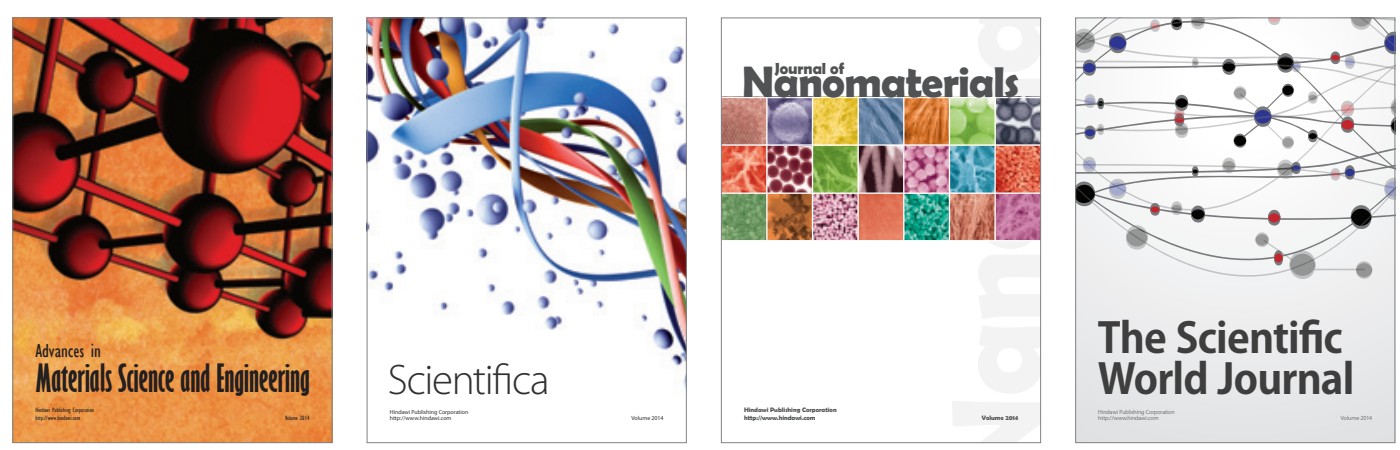

\section{The Scientific World Journal}
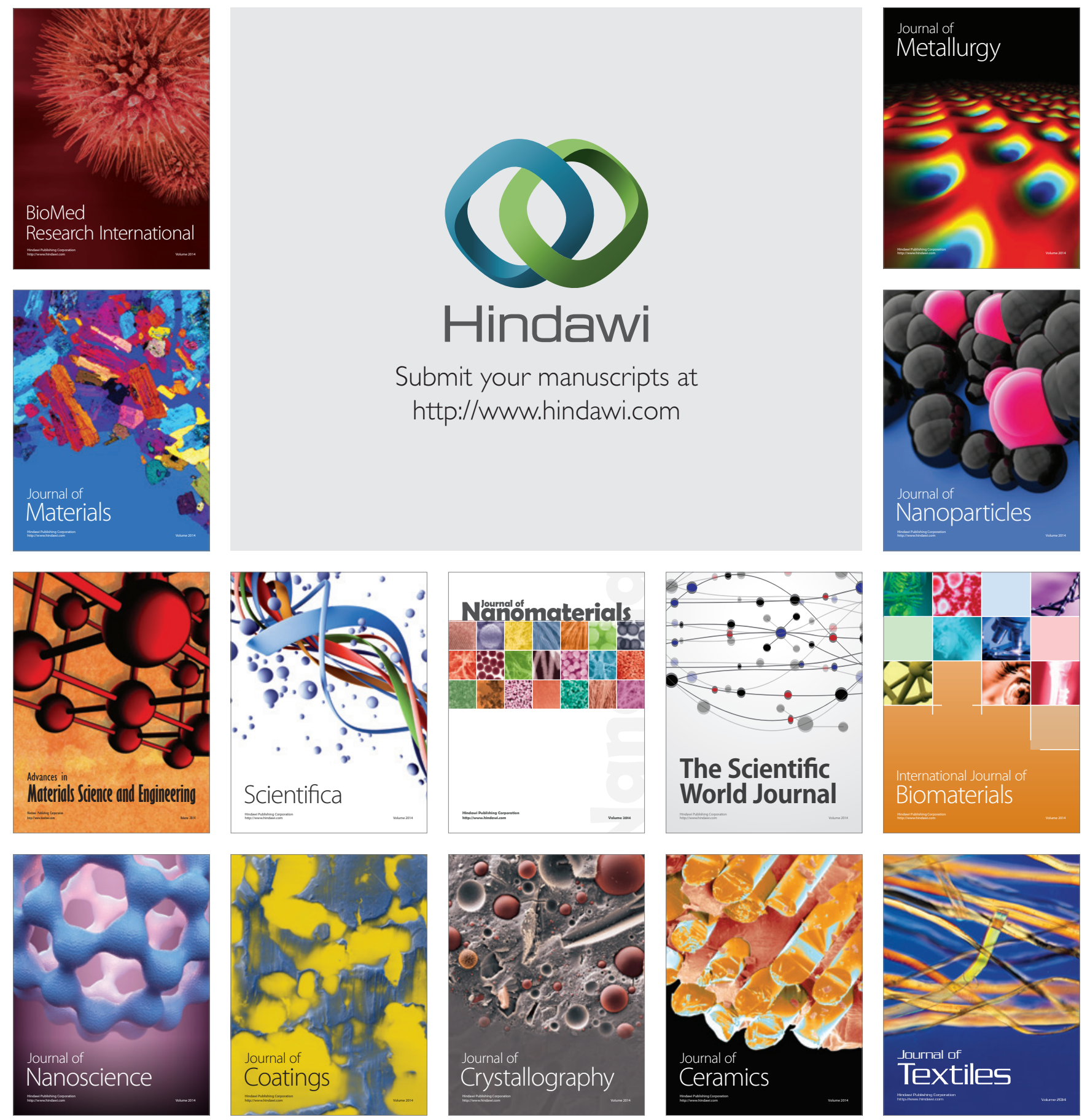